\title{
O primitivo negativo: \\ Dos animais ancestrais de Kopenawa à mostruação vazia em $O$ Congresso Futurista
}

Julian Alexander Brzozowski

UFSC

\begin{abstract}
Resumo
O presente artigo visa uma comparação em confronto da ideia de monstro encontrada na obra do xamã yanomami Davi Kopenawa $A$ queda do céu com o movimento de desideração, desastre, da caminhada intelectual do Ocidente em direção ao esvaziamento do mito e suas monstruosidades de pura aparecência que pululam o imaginário do filme O Congresso Futurista. Apoiado fortemente na elaboração de Jacques Lacan sobre o interesse do mito de dar conta de um único objeto, que é objeto de desejo, percorremos o trilho teórico do esgotamento de sentido do mundo em Jean-Luc Nancy em direção à noção do corpo enquanto arrealidade concentradora da potência cosmológica outrora reservada aos astros.
\end{abstract}

Palavras-chave: Xamanismo; Mitologia; Psicanálise; Desastre.

\begin{abstract}
The present article works on a comparison by confrontation of the depiction of the monster figure as found in the work of the yanomami shaman Davi Kopenawa The Falling Sky with the movement of desideration, disaster, of the intellectual path of the Occident towards the emptiness of myth and its monstrosities of pure appearance that populate the image of the film The Congress. Leaning strongly on the elaboration of Jacques Lacan about the interest of myth in dealing with a single object, which is the object of desire, we walk down the theoretical track of the exhaustion of sense in Jean-Luc Nancy towards the notion of the body as areality which now focuses the cosmological potency once bound to the stars.
\end{abstract}

Keywords: Shamanism; Mythology; Psychoanalysis; Disaster. 


\section{Tornar-se fantasma: Kopenawa com Warburg}

\section{La chute du ciel: Paroles d'un chaman yanomami, 2010.}

2. The falling sky: words of a yanomami shaman, Trad. Nicholas Elliott, 2013.

3. Eduardo Viveiros de Castro apud ALBERT, Bruce, KOPENAWA, Davi. A queda do céu, 2015, p. 27.
No ano de 2015 foi publicado, pela Companhia das Letras na tradução de Beatriz Perrone-Moisés, a obra $A$ queda do céu: palavras de um xamã yanomami, ditada pelo xamã e ativista político Davi Kopenawa e redigida pelo etnólogo francês Bruce Albert. Aterrissando em terras brasileiras cinco anos após sua publicação original em francês pela editora Plon ${ }^{1}$ e dois anos após sua versão estadunidense pela Harvard University Press ${ }^{2}, A$ queda do céu vem se provando objeto de estudo ímpar, ao tornar disponível o acesso a um poético e rigoroso testemunho de uma singular cultura através de outros meios que não os da imersão etnográfica. Como Viveiros de Castro o apresenta, em seu prefácio:

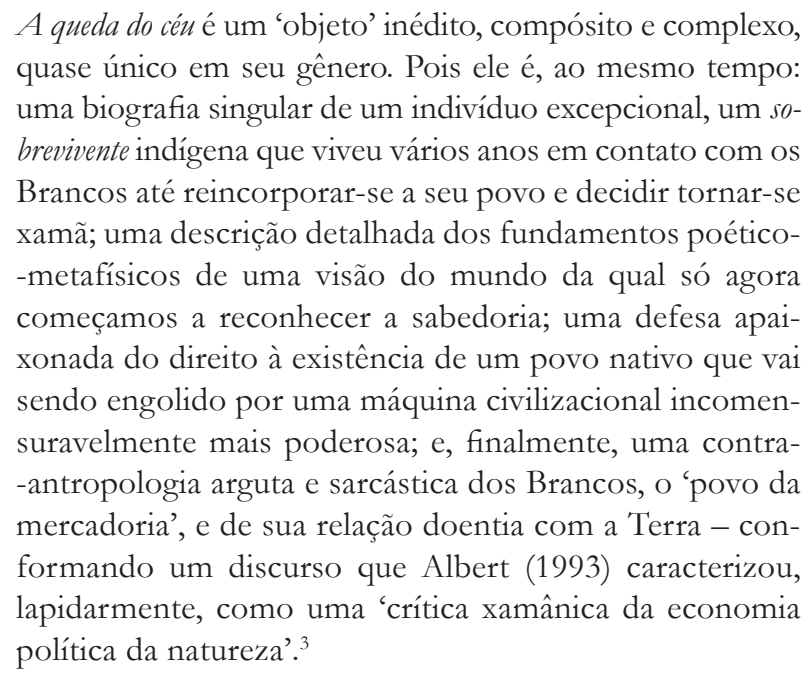

Para além desses interesses contemplados por Viveiros em sua descrição da obra, uma quinta fatia estética do livro poderia ser pensada como sua parte técnica, na qual Kopenawa se ocupa em fabular sobre as operações xamânicas, suas ferramentas artísticas e realizações. Neste processo, aparece de maneira evidente a implicação das criaturas remetentes ao tempo mitológico yanomami e sua fundamental participação no processo de cura xamânica, na introdução dos espíritos malfeitores em um sistema poético que comporta imediatamente a doença e sua terapia, a embriogênese cosmológica e a resolução psíquica do mal-estar que afeta o corpo singular. Quando Davi Kopenawa descreve a matéria a ser utilizada na operação xamânica, refere-se às imagens (utupè) dos animais ancestrais:

As imagens de animais que os xamãs fazem dançar não são dos animais que caçamos. São de seus pais, que passaram a existir no primeiro tempo. São, como disse, as imagens 
dos ancestrais animais que chamamos yarori. Há muito e muito tempo, quando a floresta ainda era jovem, nossos antepassados, que eram humanos com nomes animais, se metamorfosearam em caça. Humanos-queixada viraram queixadas; humanos-veado viraram veados; humanos-cutia viraram cutias. Foram suas peles que se tornaram as dos queixadas, veados e cutias que moram na floresta. ${ }^{4}$

As notas de Bruce Albert que acompanham a palavra yarori, referentes aos capítulos 2 - O primeiro xamã, e 4 - Os ancestrais animais, nos são de extrema importância:

De yaro, (animal de) caça, seguido do sufixo -ri (pl. pè), que denota o que se refere ao tempo das origens, não humano, superlativo, monstruoso ou de extrema intensidade. Esses ancestrais (në pata $p \ddot{e}$ ) compunham a primeira humanidade, que foi se transformando paulatinamente em caça, em razão de seu comportamento desregrado. Trata-se, na mitologia yanomami, de seres cuja forma pré-humana, sempre instável, está sujeita a uma irresistível propensão ao "devir animal" (yaroprai). De modo geral, os comportamentos que precipitam tais metamorfoses ( $x i$ wari-) invertem as normais sociais atuais, particularmente as que regem as relações entre afins. São as imagens (utupee) desses seres primordiais que são convocadas como entidades ("espíritos") xamânicas (xapiri). [...] Portanto, yarori (pl. pee) designa ao mesmo tempo os ancestrais animais mitológicos (os "pais dos animais", yaro bwiïe pè) e suas imagens (utupè) tornadas entidades xamânicas ( $x a$ piri). Essa triangulação ontológica entre ancestrais animais (yarori pè), animais de caça (yaro pè) e imagens xamânicas animais (também yarori pè) constitui uma das dimensões fundamentais da cosmologia yanomami. ${ }^{5}$

Os animais ancestrais, monstruosos seres metamórficos cuja humanidade não consegue resistir ao devir animal, não se separam semanticamente de suas imagens, utupë: na tradução de Albert do termo, "'imagem corpórea, essência vital, forma mítica primordial', e também 'reflexo, sombra, eco, miniatura, réplica, reprodução, desenho" " Um monstro que não se difere de sua mostruação, portanto: um monstro cuja essência vital é sua própria aparecência monstruosa, sua qualidade imagética indissociável de seu corpo.

A operação xamânica yanomami, descrita por Kopenawa, consiste em fazer descer as imagens (utupè) dos yarori tornadas entidades antropoformes ${ }^{7}$, os xapiri, para que através da dança e do canto o xamã possa recrutá-los na teatral guerra a ser travada na esfera espiritual. O mal a ser apaziguado aparece, na dimensão terrena do corpo, sob a forma de doenças; mas esta é apenas a consequência de querelas que se dão neste outro plano, imagético por excelência, onde ocorre a performance xamânica. A qualidade passional da embriagada dança xamânica, que ativa uma
4. KOPENAWA, Davi. A queda

do céu, 2015, 117.

5. Ibidem, p. 614-621.

6. Ibidem, p. 621.

7. Seria incorreto dizer "antropomórfica" para xapiri, tendo em vista a inconstância do litoral entre humano e não-humano para a cultura yanomami. Entretanto, os xapiri pë diferem dos yarori pë por serem caracterizados visualmente como humanos, ornamentados tal qual os xamãs, com caudais de arara nos braços, rabo de macaco cuxiú negro amarrado na testa, penugens brancas no cabelo negro e pinturas corporais de urucum. Ibidem, p. 122. 
8. DIDI-HUBERMAN, Georges. A imagem sobrevivente, 2013 [2002], p. 193-6.

9. Ibidem, p. 201.

10. Ibidem, p. 202.

11. Ibidem, p. 261-2. conversa ancestral com os xapiri, lança a sensibilidade artística do xamã em direção a um monstruoso primitivo, cujo correlato atual pode ser encontrado nos animais de caça.

Uma versão amazônica de Warburg com Darwin, portanto?

[...] [A] questão antropológica também se apresentou a Warburg em termos de primitivismo natural: porventura a dor trágica de Laocoonte não manifesta - "sublimando-a", como dizia, a exemplo de Freud, o historiador das Pathosformeln - uma relação ainda mais primordial? Não seria essa relação, infrassimbólica e infranarrativa, a do corpo humano com o sofrimento físico e com a violência da luta animal? Percebe-se que a proximidade entre o bumano e o animal constitui um tema essencial do Laocoonte, bem como do ritual indígena estudado por Warburg: nos dois casos, o homem enfrenta o animal como um perigo mortal por excelência. Também nos dois casos, o homem incorpora ou se reveste do animal, fazendo de sua própria morte - ou melhor, do instrumento dela - uma espécie de segunda pele: na estátua helênica [o Laocoonte], as serpentes mostram-se quase como uma "sobremusculatura" dos três personagens, ou suas vísceras tornam-se visíveis por uma espécie de inversão fantasmática do dentro e do fora. No ritual da serpente, o animal é apresentado como uma coisa com que o homem se enfeita e cuja substância ele se torna capaz ainda que artificialmente - de absorver. ${ }^{8}$

O trecho destacado é retirado do capítulo intitulado Gestos memorativos, deslocados, reversivos: Warburg com Darwin, d'A imagem sobrevivente de Didi-Huberman, dedicado à leitura de Warburg sobre $A$ Expressão das emocões no homem e nos animais de Darwin. O interesse de Warburg pela obra, entretanto, em nada se baseia no interesse positivista de uma pretensa evolução das formas da arte. Da maneira pulsante que lhe é própria, Warburg encontra em Darwin a possibilidade de leitura do Laocoonte "pelo ângulo da sobrevivência do primitivo", através de um "princípio dialético do gesto expressivo"10, que muito se aproxima de uma versão instintual do mesmo jogo de forças conflitantes que Freud leu nas performances das histéricas de Charcot $^{11}$.

Ao tratar da sobrevivência de fantasmas primitivos, Warburg se aproxima do léxico de Kopenawa. Este, ao sorver do pó de yãkoana que lhe permite entrar em contato com os xapiri, fala sobre entrar "em estado de fantasma":

[Quando criança] ficava muito curioso quanto ao que poderia ver. Deitava em minha rede e ficava assim, parado. Aos poucos ia virando fantasma e, quando anoitecia, sonhava sem parar. Então, podia ver as magníficas imagens dos ancestrais animais, dos espíritos do céu e dos rios. Isso me acontecia muitas vezes, pois quando eu era pequeno, 
gostava de experimentar o pó de yãkoana. Foi assim que me fizeram crescer. ${ }^{12}$

12. KOPENAWA, Davi. A queda do céu, 2015, p. 97-8.

13. VIVEIROS DE CASTRO, Eduardo. Metafísicas canibais, 2015, p. 173-4.

\section{DIDI-HUBERMAN,} Georges. A imagem sobrevivente, 2013, p.115.

15. KOPENAWA, Davi. A queda do céu, 2015, p. 98.

16. Em suas Memórias da viagem à região dos índios Pueblos na América do Norte: "O formato serpentino do raio, o enigma de seu movimento (que não possui um ponto de partida e de chegada que se possa determinar com nitidez), seu perigo - isso tudo o raio compartilha com a serpente, que proporciona um máximo de movimento e um mínimo de superfície vulnerável. WARBURG, Aby. Histórias de fantasma para gente grande, [1923] 2010, p. 263. 
17. VIVEIROS DE CASTRO, Eduardo. Metafísicas canibais, 2015, p. 58.

18. DIDI-HUBERMAN, Georges. A imagem sobrevivente, 2013, p. 38.

19. AGAMBEN, Giorgio. Infância e história, [1978] 2008, p. 60. é anterior à forma, a relação é superior aos termos, e o intervalo é interior ao ser" ${ }^{\prime 17}$. Ao encarnar uma instância mitológica, é a esse tempo que Kopenawa reporta: uma verdadeira sopa de enguias warburguiana ${ }^{18}$.

\section{O Ocidente afugenta o mito: $O$ congresso futurista e a monstruosi- dade da pura aparecência}

$\mathrm{Na}$ leitura que combina Warburg e Kopenawa podemos, portanto, ler algo de uma torção estética monstruosa quando o primitivo é colocado em questão. No caso do xamã, a noção do primitivo é pensada como um regime de intensa alteridade metamórfica, na intermitência constante entre o humano e o animal. Em Warburg, a animalidade ancestral é pinçada da teoria darwiniana, mas para extrair dali uma ideia muscular de traços circundantes ao jogo de forças dialético que orienta a Pathosformeln, em detrimento da noção positivista que uma teoria evolucionista das formas da arte poderia evocar.

À parte de uma ancestralidade estética ou muscular que denota a óbvia afinidade corpórea do humano com relação ao animal, a ideia de um momento da infância humana, um arcaísmo pré-linguístico real, ainda não apresenta evidência alguma aos estudos linguísticos. Conforme a citação de Émile Benveniste, que Agamben trabalha em Infância e História:

\footnotetext{
"Nós tendemos sempre para essa imaginação ingênua de um período original em que um homem completo descobriu um seu semelhante, igualmente completo, e entre eles, pouco a pouco tomaria forma a linguagem. Isto é pura fantasia. Nós não encontramos jamais o homem separado da linguagem e não o vemos jamais no ato de inventá-la... É um homem falante que nós encontramos no mundo, um homem que fala a outro homem, e a linguagem ensina a própria definição do homem." É através da linguagem, portanto, que o homem como nós o conhecemos se constitui como homem, e a linguística, por mais que remonte ao passado, não chega nunca a um início cronológico da linguagem, a um "antes" da linguagem. ${ }^{19}$
}

Uma relevante consideração, quando pensamos nas formas que essa ascensão estética ao primitivo pode assumir na modernidade.

Ao trabalhar a dor trágica sublimada do Laocoonte, nas vísceras tornadas serpentes como objeto visual sublimado, podemos aplicar a tal leitura a fórmula lacaniana da sublimação, 
conforme apresentada no Seminário 7: a elevação de um objeto à dignidade de Coisa ${ }^{20}$. Ora, a Coisa é nada menos que o mais prístino dos objetos humanos, uma fugidia esfera de negatividade. Lacan evoca a imagem do oleiro, a "função artística talvez mais primitiva" 21 , como aquele que "cria o vaso em torno desse vazio com sua mão, o cria assim como o criador mítico, ex nibilo, a partir do furo", para pensar o vaso "como um objeto feito para representar a existência do vazio no centro do real que se chama a Coisa"22. Um vórtice de negatividade, portanto.

$\mathrm{Na}$ operação da sublimação, entretanto, há sempre uma lacuna entre objeto sublimado e a Coisa (um resto, para dizê-lo com Agamben ${ }^{23}$ ): um espaçamento estético de abundância formal, ostentando infinitas máscaras. A Coisa nua ganha status mítico, como objeto de zoé; mas a sensibilidade humana, que não suporta seu olhar, a recobre de representações para que possa lidar com a monumental ausência de sentido concreto, universal, que lhe sustenta.

Em seu Seminário 4, Lacan explora a função ficcional do mito e sua fundamental imbricação com o florescimento da potência significante no homem:

Os mitos, tais como se apresentam em sua ficção, visam sempre mais ou menos, não à origem individual do homem, mas à sua origem específica, à criação do homem, à gênese de suas relações nutrizes fundamentais, à invenção dos grandes recursos humanos, ao fogo, à agricultura, à domesticação dos animais. Encontramos aí também, constantemente questionada, a relação do homem com uma força secreta, maléfica ou benéfica, mas essencialmente caracterizada pelo que tem de sagrado. [...] Essa potência sagrada, diversamente designada nos relatos míticos que explicam como o homem adveio em relação a ela, deixa-se situar para nós numa identidade manifesta com o poder da significação, e muito especialmente, de seu instrumento significante. Essa é a potência que faz o homem capaz de introduzir na natureza aquilo que une o próximo e o distante como o homem e o universo, capaz também de introduzir na ordem natural, não somente suas próprias necessidades e os fatores de transformação a elas submetidos, mas a noção, que vai mais além, de uma identidade profunda, jamais apreendida minimamente entre, por um lado, o poder que ele tem de manejar o significante ou ser por este manejado, incluir-se num significante, e, por outro lado, o poder que ele tem de encarnar a instância desse significante em uma série de intervenções que não se apresentam, originalmente, como atividades gratuitas, quero dizer, de realizar a pura e simples introdução do instrumento significante na cadeia das coisas naturais. ${ }^{24}$

Unindo o pensamento de Benveniste e Agamben às formulações de Lacan, chegamos ao estatuto do mito no ocidente
20. LACAN, Jacques.

O Seminário, Livro 7: A Ética

da psicanálise, [1959-1960] 2008, p.137.

21. Ibidem, p. 146.

22. Ibidem, p. 148.

23. AGAMBEN, Giorgio. O que resta de Auschwitr, 2008.

24. LACAN, Jacques. $O$

Seminário, Livro 4: A Relação de objeto, [1956-1957], 1995, p. 259-60. 
25. Em O Estádio do espelho, de 1949, Lacan desbanca a inutilidade do cume filosófico existencialista: "Ao cabo do projeto histórico de uma sociedade de não mais reconhecer em si outra função que não a utilitária, e na angústia do invidíduo diante da forma concentracionista do vínculo social cujo surgimento parece recompensar esse esforço, o existencialismo julga-se pelas justificativas que dá para os impasses subjetivos que, a rigor, resultam dele: uma liberdade que nunca se afirma tão autêntica quanto dentro dos muros de uma prisão, uma exigência de engajamento em que se exprime a impotência da consciência pura de superar qualquer situação, uma idealização voyeuristasádica da relação sexual, uma personalidade que só se realiza no suicídio, e uma consciência do outro que só se satisfaz pelo assassinato hegeliano. A essas proposições opõe-se toda nossa experiência”. LACAN, Jacques. Escritos, [1960] 1998, p. 102.

26. LACAN, Jacques. $O$ Seminário, Livro 10: A Angústia, [1962-1963] 2005, p. 47.

27. LACAN, Jacques. O Seminário, Livro 14: A Lógica do fantasma, [1966-1967] 2008, p. 15.

28. NANCY, Jean-Luc. El sentido del mundo, [1993] 2003, p. 72.

29. Ibidem, p. 62. moderno. A função da ficção mitológica pretende prestar contas à maneira segundo a qual o homem adveio em relação a linguagem, a potência de significação, de manejo do significante. Benveniste e Agamben desbancam a fantasia desse tempo pré-linguístico em que consistiria o passado mitológico: não há um antes da linguagem, o humano está desde sempre imerso nela. Quando o humano confecciona o significante tal qual o vaso de cerâmica, é um furo que o sustenta: a Coisa é que está em seu cerne. Entretanto, ainda que a expressão usada para aludir a tal objeto seja ex nibilo, a teoria lacaniana não leva águas ao moinho niilista do existencialismo, ao qual Lacan se opunha firmemen$\mathrm{te}^{25}$. Contrariamente, ele afirma que a teorização sobre o mito "tem seu valor, desde que saibamos que se trata da relação com o objeto que tem status de objeto de desejo" ${ }^{26}$. Ou seja, desde que saibamos que o correlato da Coisa mítica no nível carnal, ou a maneira segundo a qual o homem adveio (singularmente) em relação a potência significante, é o objeto $a$, a saber: "o seio, o cíbalo, o olhar, a voz, essas peças destacáveis e, contudo, fundamentalmente religadas ao corpo: eis o do que se trata no objeto $a " 27$.

Trata-se, em outras palavras, da história do desastre de que fala Nancy em O Sentido do mundo: o movimento de queda da orientação celeste através dos astros em direção ao corpo, ao desiderium que engendra o desejo ${ }^{28}$. $\mathrm{Na}$ impossibilidade de se admitir um sentido mitológico do mundo, de se pensar o mundo pressionado por uma força narrativa vetorial em direção a um além-mundo, um outro do mundo, é o mundo mesmo que passa a ser sentido. Este sentido só se dá no ser singular plural de cada corpo:

Ser se siente y se sabe ser: se puede decir perfectamente que aquí está el sentido mismo. Pero esto mismo no se siente ni se sabe bajo ningún modo de la apropiación sintiente o sapiente. Esto no hace sentido, no significa y no se significa. Ser llega, pero no se allega y no se recuerda - no sin resto. $\mathrm{Y}$ sin que esto lo prive de nada. O bien: ser tiene lugar, pero su lugar lo espacía. Ser cada vez es un área, su realidad se da en arrealidad. Es así que ser es cuerpo. No 'incorporado' ni 'encarnado', ni siquiera en 'cuerpo propio': sino cuerpo, contando en su saber, por lo tanto, su propio afuera, diferente. ${ }^{29}$

Ou seja, a negatividade do furo cerâmico da Coisa em verdade nada priva o ser do corpo, que vive no resto, na lacuna estético-lingústica que é seu próprio espaçamento: sua arrealidade. Isso desvia a atenção do abismo do ser em direção às infinitesalmente coloridas máscaras que o objeto de desejo do corpo pode assumir.

O Congresso Futurista (The Congress), filme de 2013 do diretor israelense Ari Folman, explora as monstruosas consequências 
que tal noção do ser e do corpo pode ter. Baseado no livro Kongres futurologiczny (1971) do escritor polonês Stanisław Lem, o Congresso apresenta, sob o artifício da animação, um futuro no qual humanos assumiram a qualidade de imagens manipuláveis através do consumo de químicos específicos. Cada um projeta para o exterior uma vontade imagética e, atendendo o desejo individual, é possível proporcionar qualquer tipo de gozo estético vivenciado sob a forma de imagem. Como explica o personagem de Dylan (Jon Hamm), guia da desavisada protagonista reminiscente de um passado do qual somos contemporâneos:

Não há mais ego. Graças a química, fomos redimidos. Não há mais ego, competição, violência, guerra, fortes ou fracos, segredos... Todos são o que são. Todo mundo é o que quer ser. E enquanto consomem sua nova personalidade, eles espalham no ar feromônios, que a sua mente traduz numa imagem. [...] Há um ano, quando eu estava consumindo mitologia grega, eu acordei metade homem, metade deus. Engravidei uma das filhas de Zeus, dei luz à uma cidade inteira e depois eu fodi a cidade, a queimei e a castiguei! É tudo sentimento! ${ }^{30}$

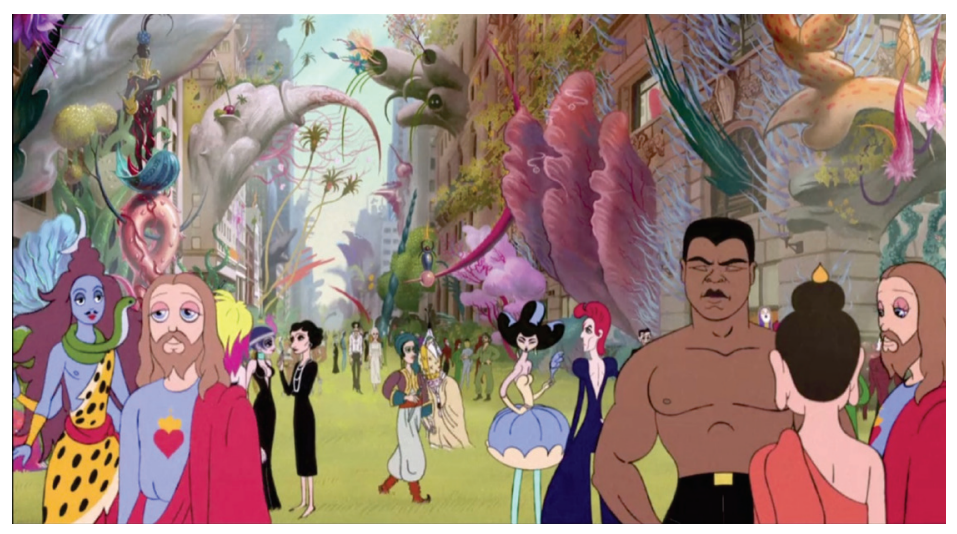

Fig. 1: Os habitantes imagéticos do futuro apresentado em $O$ Congresso Futurista (2013).

Diríamos: é tudo gozo, solitário gozo imagético que esteriliza a linguagem e domestica completamente o Outro. Os feromônios químicos exalados por cada um são traduzidos em imagens baseadas na biblioteca estética individual do receptor: as dobras estéticas que envolvem os singulares objetos $a$ de cada transeunte irão projetar a aparência imagética de cada outro (tornado mesmo), inserindo-o em uma mitologia individual completamente esvaziada de sentido narrativo: não há mais segredos. O humano, aí, fez de sua extraordinária capacidade de formular imagens e com elas aceder ao gozo uma pura e vazia aparecência; são todos monstruosos mostruários na forma de espelhos narcísicos (Fig. 1). A qualidade de extrema reflexividade estética do regime sensível d'O Congresso coloca em questão
30. Minutação: $1 \mathrm{~h} 31 \mathrm{~m}$. The Congress. Dir.: Ari Folman, Pandora Filmproduktion, 2013. 
31. RANCIÈRE, Jacques. $O$

Destino das imagens, [2003] 2012, p. 9 .

32. NANCY, Jean-Luc. El sentido del mundo, 2003, p. 46.

33. NANCY, Jean-Luc. El intruso, [2000] 2006, p. 12-3. até mesmo seu estatuto de imagem, como nos sugere Rancière sobre o apocalipse das imagens: "se só há imagens, não existe mais um outro da imagem. E se não existe mais um outro da imagem, a noção mesma de imagem perde seu conteúdo, não há mais imagem" 31 .

A desideração, o desastre mitológico, esse processo histórico, intelectual e sensível surge:

a partir de una formidable necesidad de poner en escena el sentido del sentido, de figurarlo, de agitar sus máscaras, sus destellos, sus trayectorias, en una dramatización intensa cuyo recurso es Occidente mismo en tanto oscurecimiento originario del sentido: interrupción del mito y del sacrificio, que se convierte en aquello que Occidente sólo puede mimar (es lo que dice de sí mismo). ${ }^{32}$

Entretanto, essa translação dos astros em direção ao corpo, movimento fundador do desejo, só será compreendido em toda sua radicalidade ao observarmos que a instância de Outro do mundo também desabou da abóboda celeste e se instalou no desejo. Este é um lugar comum para a psicanálise, e em grande medida é nisso que insistem Warburg e Kopenawa: tanto a sobrevivência do primitivo manifesta na contração muscular inconsciente quanto o regime de metamorfose efervescente dos yarori apontam fundamentalmente para uma imprescindibilidade estética da esfera do outro, que deverá ser mantido em sua resiliente qualidade de intruso ${ }^{33}$. Só assim a desejada emancipação do homem em direção ao livre sonhar poderá evitar de se tornar a maquinação narcísica do espelho em perpétuo gozo auto-erótico.

O sono da razão produz, monstros. Bem, contanto que sejam outros monstros e não os mesmos, seguimos.

\section{Referências}

AGAMBEN, Giorgio. Infância e história: destruição da experiência e origem da história. Tradução: Henrique Burigo. Belo Horizonte: Ed. UFMG, 2005. O que resta de Auschwitr. Tradução: Selvino J. Assmann. São Paulo: Boitempo Editorial, 2008.

ALBERT, Bruce; KOPENAWA, Davi. A queda do cén: palavras de um xamã yanomami. Tradução: Beatriz Perrone-Moisés, São Paulo: Companhia das Letras, 2015. 
DIDI-HUBERMAN, Georges. A imagem sobrevivente: História da arte e tempo dos fantasmas segundo Aby Warburg. Tradução: Vera Ribeiro, Rio de Janeiro: Contraponto Editora, 2013.

LACAN, Jacques. Escritos. Tradução: Vera Ribeiro, Rio de Janeiro: Zahar, 1998. - O Seminário Livro 4: A relação de objeto. Tradução:

Dulce Duque Estrada, Rio de Janeiro: Zahar, 1995. - O Seminário: Livro 7, A Ética da Psicanálise.

Tradução: Antônio Quinet. São Paulo: Jorge Zahar, 2008. - O Seminário: Livro 10, A Angústia. Tradução: Vera

Ribeiro. Rio De Janeiro: Zahar, 2005. - O Seminário: Livro 14, A Lógica do Fantasma.

Tradução: Amélia Lyra, Conceição Beltrão Fleig, Dulcinéa de Andrade Lima Araújo, Irma Chaves, Ivan Corrêa, Letícia P. Fonsêca, Luiz Alberto Tavares, $\mathrm{M}^{\mathrm{a}}$ Lúcia de Queiroz Santos, Mario Fleig. Recife: Centro de Estudos Freudianos do Recife, 2008.

NANCY, Jean-Luc. El Sentido Del Mundo. Tradução: Jorge Manuel Casas, Buenos Aires: la marca editora, 2003. - El intruso. Tradução: Margarita Martínez, Buenos

Aires: Amorrortu, 2006.

RANCIÈRE, Jacques. O Destino das Imagens. Tradução: Mônica Costa Netto. Rio de Janeiro: Contraponto, 2012.

VIVEIROS DE CASTRO, Eduardo. Metafísicas Canibais, São Paulo: Cosac Naify, 2015.

WARBURG, Aby. Histórias de fantasma para gente grande: escritos, esboços e conferências. Org.: Leopoldo Waizbort, Tradução: Lenin Bicudo Bárbara, São Paulo: Companhia das Letras, 2010. 
